\title{
MENANAMKAN RASA PEDULI TERHADAP LINGKUNGAN DIMULAI DARI KECIL
}

\author{
Surya Hermawan ${ }^{1 *}$, Sentosa Purnomo ${ }^{1}$, Patricia Sally ${ }^{1}$, Diky Riesky $^{1}$ \\ ${ }^{1}$ Fakultas Teknik Sipil dan Perencanaan, Universitas Kristen Petra \\ Jl. Siwalankerto 121-131, Surabaya 60236, Indonesia \\ * Penulis korespondensi; E-mail: surya@petra.ac.id
}

\begin{abstract}
Abstrak: Seiring perkembangan waktu, banyak orang berlomba-lomba untuk menetap di kota besar. Hal ini dikarenakan banyak yang beranggapan bahwa kehidupan di kota lebih modern dilengkapi dengan sarana dan prasarana yang lebih lengkap. Selain itu, lapangan pekerjaan yang tersedia di kota besar juga diharapkan dapat mencukupi kebutuhan mereka. Namun, tanpa disadari akan muncul masalah baru. Tingginya aktivitas urbanisasi tidak dapat diimbangi dengan pertambahan lahan yang terbatas. Sehingga terbentuk permukiman baru di pinggiran kota dan mayoritas dengan memanfaatkan lahan yang sempit sehingga tidak memenuhi persyaratan kesehatan dan muncul masalah kebersihan. Contohnya, dalam hal sampah. Masyarakat seringkali membuang sampah di selokan ataupun kali kecil karena kurangnya kesadaran untuk menjaga kebersihan, disebabkan karena kurangnya pendidikan mengenai kepedulian dan memang kurang tersedianya fasilitas tempat sampah. Hal ini yang menjadi dasar dan tujuan dari diadakannya pengabdian masyarakat bermetode service learning, yaitu untuk membantu masyarakat yang membutuhkan dan mengajak mereka untuk meningkatkan rasa kepedulian terhadap orang lain dan lingkungan. Kegiatan ini berlokasi di daerah Kelurahan Putat Jaya, Surabaya yang sebelumnya merupakan daerah lokalisasi Dolly. Kegiatan ini sendiri bertujuan untuk mengenalkan anak-anak mengenai lingkungan yang bersih dan sehat guna menumbuhkan rasa peduli terhadap lingkungan dimulai dari usia dini. Ada beberapa metode yang dilakukan, di antaranya adalah mengajak anak-anak kelas 1-3 SD untuk berpartisipasi dalam lomba mewarnai, anak-anak kelas 4-6 SD lomba menghias tempat sampah, dan 4 kolam lele yang diberikan untuk masyarakat setempat. Hasil dari kegiatan ini sesuai dan menjawab tujuan awal dari kegiatan, yaitu menumbuhkan dan meningkatkan rasa peduli terhadap sesama dan lingkungan.
\end{abstract}

Kata kunci: Rasa peduli, lingkungan, kecil, eks dolly, surabaya.

\begin{abstract}
Over time, many people are competing to live in big cities. It causes many people to assume that life in a more modern city equipped with more complete facilities and infrastructure. Also, the jobs available in big cities are expected to be able to meet their needs. However, unwittingly new problems will arise. The high level of urbanisation cannot match by limited land accretion. So that new settlements are formed in the suburbs, and the majority use narrow land so that it does not meet health requirements and hygiene problems arise. For example, in the case of garbage. The community often throws rubbish in the gutter or short times due to lack of awareness to maintain cleanliness, due to lack of education about caring and indeed lack of trash facilities. It is the basis and purpose of holding community service learning methods, which is to help people in need and invite them to raise a sense of concern for others and the environment. This activity located in the Putat Jaya Kelurahan, Surabaya, which was previously the Dolly localisation area. This activity itself aims to introduce children to a clean and healthy environment to foster a sense of caring for the environment starting from an early age. There are several methods carried out, including inviting children in grades 1-3 to participate in colouring competitions, grades 4-6 elementary school students to decorate trash cans and four catfish ponds given to the local community. The results of this activity are following and answer the initial purpose of the activity, which is to grow and increase caring for others and the environment.
\end{abstract}

Keywords: Caring, environment, small, ex dolly, surabaya.

\section{PENDAHULUAN}

Pertumbuhan jumlah penduduk yang pesat dan tidak diimbangi dengan ketersediaan lahan untuk permukiman seringkali menjadi masalah yang timbul saat ini. Masalah perekonomian di
Indonesia juga menjadi salah satu pemicu banyaknya penduduk dari desa yang bermigrasi ke daerah perkotaan dengan harapan dapat meningkatkan kualitas kehidupan mereka (Greentumble, 2016; MateriIPS.com, 2017). Begitu juga Damianus (2017) mengungkapkan bahwa pertumbuhan urbanisasi di 
Indonesia saat ini adalah sebesar 4,1 persen. Angka tersebut lebih tinggi daripada pertumbuhan urbanisasi di Tiongkok yang sebesar 3,8 persen dan India 3,1 persen. Tanpa memperhatikan ketersediaan lahan yang terbatas di perkotaan, mereka tetap membangun permukiman di pinggiran kota dengan memanfaatkan lahan yang sempit (Wikipedia Bahasa Indonesia, 2018; Arjuna, 2013).

Dari fakta yang ada, pertumbuhan ini seharusnya bisa menjadi modal bagi Indonesia jika tata kelolanya baik. Sangat disayangkan karena justru pertumbuhan yang relatif tinggi itu ternyata tidak diiringi dengan kemampuan tata kelola dan infrastruktur yang memadai. Misalnya adalah pembangunan infrastruktur yang tertinggal, kemacetan parah di kota-kota besar, serta rendahnya kualitas alat transportasi. Masalah-masalah tersebut dapat terjadi karena semakin banyaknya daerah-daerah permukiman di pinggiran kota dan mayoritas dibangun di dekat tepi sungai atau kali kecil. Hal ini dapat mengganggu lingkungan karena fasilitas yang tersedia kurang memadai, seperti misalnya fasilitas MCK (David, 2018). Sehingga aktivitas tersebut langsung berhubungan dengan sungai ataupun kali.

Hal ini menunjukkan bahwa kebersihan menjadi kunci yang sangat penting. Di daerah pinggiran Kota Surabaya sendiri, masih banyak yang kondisinya cukup memprihatinkan. Penyebab utamanya adalah kurangnya kesadaran dari masyarakat untuk menjaga kebersihan daerahnya. Dalam jangka panjang, hal ini dapat menjadi boomerang bagi lingkungan. Contoh yang paling ekstrem adalah rusaknya rantai makanan dan ekosistem di sungai. Lebih lanjut, kebersihan lingkungan yang tidak dijaga akan berdampak pada penurunan jumlah oksigen yang menjadi "nyawa" masyarakat (Robert, 2010; Alexia, 2008; Berita Nasional. 2017).

Pada akhirnya, usaha yang dapat dilakukan adalah dengan meningkatkan kesadaran dan kepedulian masyarakat terhadap lingkungannya dari segala jenis usia. Pengenalan akan lingkungan bagi anak usia dini perlu mulai dibangun agar dapat dijadikan kebiasaan yang positif kelak. Tentu dengan cara yang sederhana, mudah dipahami, dan melekat di pikiran mereka. Salah satunya adalah dengan mengadakan acara atau lomba yang membuat mereka dapat berkreasi meningkatkan imajinasi tentang lingkungan hidup dengan cara mewarnai. Hal lain yang dapat dilakukan adalah dengan menyediakan fasilitas tempat sampah dan melibatkan anak-anak untuk turut serta menghiasnya, dan diharapkan dapat mengajak mereka untuk membuang sampah pada tempatnya. Melalui kegiatan-kegiatan ini, setidaknya hal kecil yang dilakukan akan berdampak besar bagi lingkungan (Wikipedia Bahasa Inggris, 2018).
Oleh karena itu, kegiatan pengabdian masyarakat yang berfokus pada anak anak di usia dini ini dengan bermetode service learning dilaksanakan pada daerah kampung perkotaan di eks lokalisasi Dolly Putat Jaya Sawahan Kota Surabaya (Hermawan et al. 2018, Hermawan b,c,d et al. 2019). Adapun judul pengabdian masyarakatnya adalah menanamkan rasa peduli terhadap lingkungan dimulai dari kecil. Dengan adanya kegiatan ini anak kecil yang merupakan tonggak penerus bangsa memiliki rasa peduli dan tanggung jawab pada lingkungan sekitar, teristimewa pada kampung mereka sendiri. Kampung ini nantinya dapat dijadikan suatau kampung perkotaan yang tangguh dan berkelanjutan yang berasaskan lingkungan, ekonomi dan sosial (Hermawana et al. 2019). Kegiatan pengabdian masyarakat bermetode service learning yang dilakukan oleh mahasiswa Universitas Kristen Petra Program Studi Teknik Sipil yang bertempat di wilayah Putat Jaya, Surabaya memiliki beberapa tujuan, di antaranya: Anak-anak di wilayah Putat Jaya menjadi lebih sadar akan pentingnya menjaga kebersihan lingkungan, dan meningkatkan kreativitas warga terutama anak-anak di wilayah Putat Jaya.

\section{METODE PELAKSANAAN}

\section{Pra Pelaksanaan}

Pada pra-pelaksanaan service learning diadakan survei lokasi acara. Survei ini dilakukan dengan tujuan untuk mengetahui potret atau gambar dengan melihat keadaan lokasi acara agar kegiatan yang nantinya akan dilaksanakan dapat relevan dan bermanfaat. Selain itu, juga sekaligus digunakan sebagai sosialisasi kepada masyarakat tentang kegiatan yang akan dilakukan di RT mereka. Selanjutnya, hal yang dilakukan beberapa hari sebelum lomba adalah pendataan peserta yang akan mengikuti lomba. Kelompok pertama melakukan pendataan di wilayah RT 3, sedangkan kelompok kedua melakukan pendataan di wilayah RT 4. Selama pendataan, dilakukan juga briefing singkat kepada anak-anak peserta lomba tentang keperluan lomba, waktu, serta tempat lomba akan diadakan seperti yang terlihat di Gambar 1.

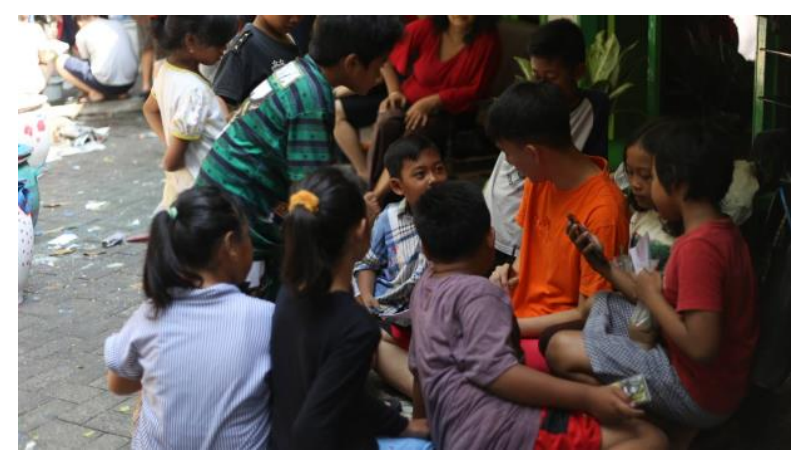

Gambar 1. Pendataan Anak-anak Peserta Lomba 


\section{Pelaksanaan}

Kegiatan service learning diadakan selama 2 hari. Pada hari pertama, dilaksanakan kegiatan membuat kolam lele untuk warga seperti terlihat pada Gambar 2. Dua kolam terletak di RT 3 dan 2 kolam terletak di RT 4. Dan pada hari kedua pelaksanaan, kegiatan lomba menggambar dimulai pada pukul 11 pagi. Sebelum kegiatan dimulai, mahasiswa pelaksana lomba menyiapkan lokasi lomba dengan mengatur tikar tempat lomba mewarnai dilaksanakan dan memindahkan tempat sampah dari mobil menuju lokasi serta menyusun koran-koran yang dijadikan alas untuk menghias tempat sampah. Menjelang lomba, peserta lomba yang telah sampai di lokasi segera diatur tempat duduknya oleh mahasiswa pelaksana lomba agar dapat bersiap-siap.

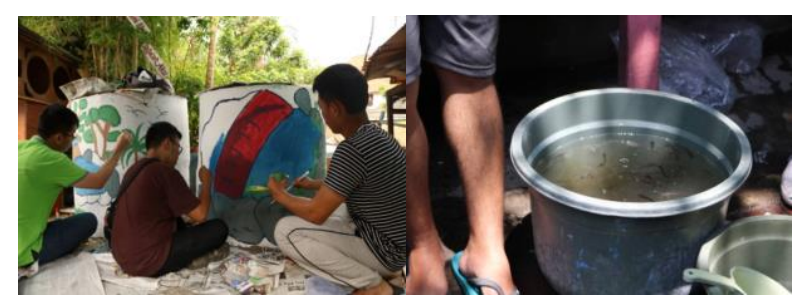

Gambar 2. Pembuatan Kolam Lele dan Bibit Lele

Kemudian, kegiatan lomba dimulai. Sepanjang kegiatan lomba, mahasiswa ikut mendampingi anak-anak peserta lomba seperti yang dapat dilihat pada Gambar 3.

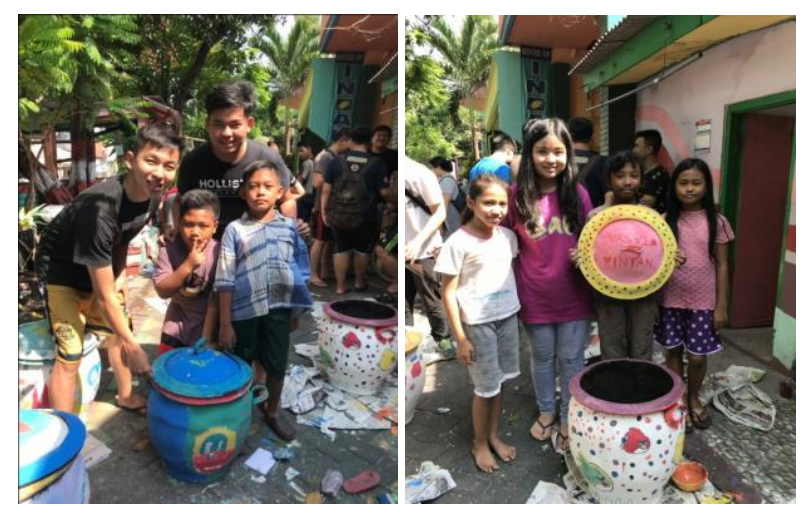

Gambar 3: Mahasiswa Mendampingi Peserta Lomba

\section{Paska Pelaksanaan}

Setelah acara lomba selesai, anak-anak peserta lomba kembali ke rumah masing-masing untuk melaksanakan sholat. Siang hari sebelum makan siang bersama, diadakan pengumuman pemenang lomba dan penyerahan hadiah kepada pemenang lomba, serta pembagian bingkisan kepada seluruh peserta lomba seperti yang terlihat pada Gambar 4. Pada akhirnya, anak-anak peserta lomba pulang dan beberapa dari mereka menunggu mahasiswa pelaksana lomba pulang.

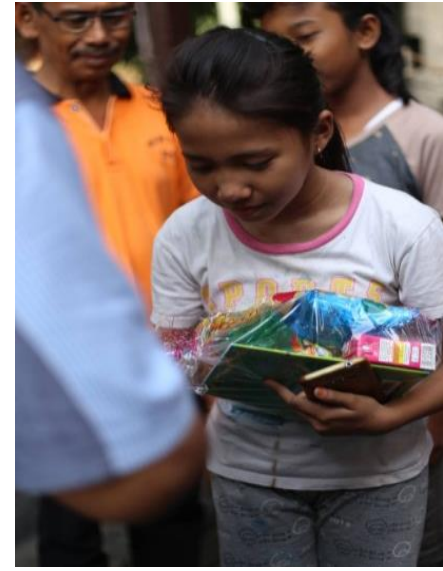

Gambar 4. Pembagian Hadiah dan Bingkisan kepada Anak-anak Peserta Lomba

\section{HASIL DAN PEMBAHASAN}

\section{Pelaksanaan Lomba}

$\begin{array}{ll}\text { Hari/Tanggal } & : \text { Sabtu-Minggu/ 10-11 November } \\ & 2018 \\ \text { Pukul } & : 10.00-16.00 \text { WIB } \\ \text { Tempat lomba } & : \text { Putat Jaya, Surabaya }\end{array}$

\section{Peserta Lomba}

Hasil dari kegiatan service learning adalah sebagai berikut:

A. Responden Berdasarkan Kategori Umur

Dilihat dari Gambar 5, total responden yang tercatat sebanyak 28 orang, jumlah responden yang tergolong kanak-kanak (6-11 tahun) ada 11 orang, remaja awal (12-16 tahun) ada 4 orang, remaja akhir (17-25 tahun) ada 5 orang, dewasa awal (26-35 tahun) ada 3 orang, dewasa akhir (36-45 tahun) ada 4 orang, dan lansia awal (4655 tahun) ada 1 orang.

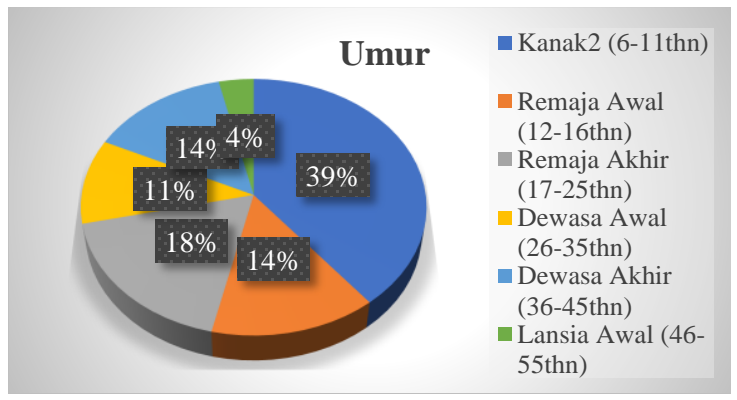

Gambar 5. Grafik Responden Berdasarkan Kategori Umur

B. Responden Berdasarkan Kategori Pekerjaan Dilihat dari Gambar 6, total responden yang tercatat sebanyak 28 orang, jumlah responden yang bekerja sebagai pelajar SD ada 12 orang, SMP ada 3 orang, SMA ada 2 orang, mahasiswa ada 1 orang, IRT ada 7 orang, wiraswasta ada 2 orang, dan yang bekerja sebagai pegawai ada 1 orang. 


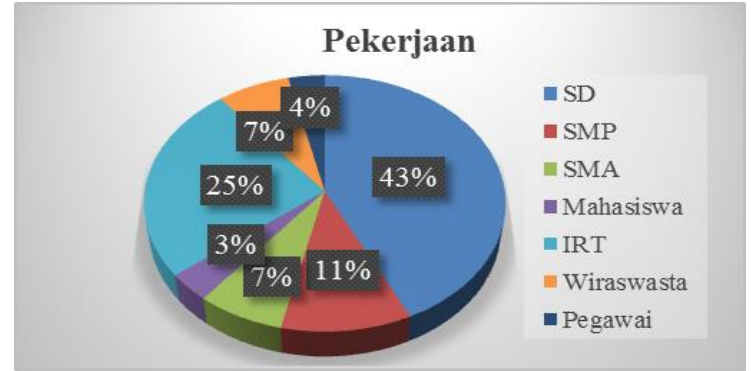

Gambar 6. Grafik Responden Berdasarkan Kategori Pekerjaan

C. Responden Berdasarkan Kategori Jenis Kelamin Dilihat dari gGambar 7, total responden yang tercatat sebanyak 28 orang, responden wanita berjumlah 17 orang, sedangkan responden pria berjumlah 11 orang.

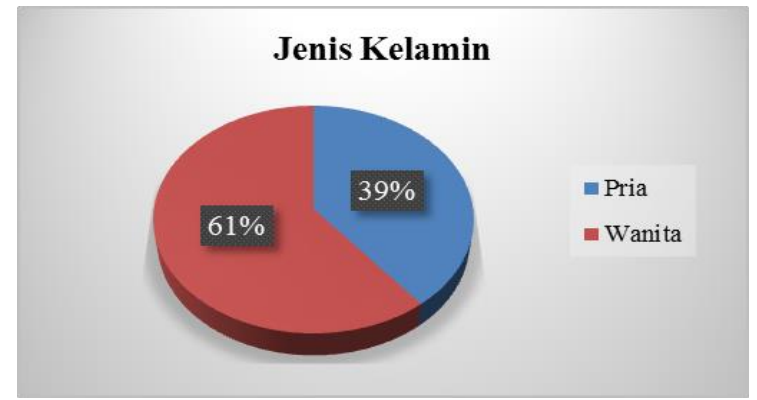

Gambar 7. Grafik Responden Berdasarkan Kategori Jenis Kelamin

\section{Kriteria Keberhasilan Kegiatan Service Learning}

1. Ide untuk topik kegiatan

Dilihat dari Gambar 8, menurut responden ide untuk topik kegiatan sangat bervariasi. $22 \%$ untuk edukasi, $21 \%$ untuk penghijauan, $18 \%$ untuk kebersihan, 7\% untuk mempercantik kampong, dan $32 \%$ untuk alasan lainnya.

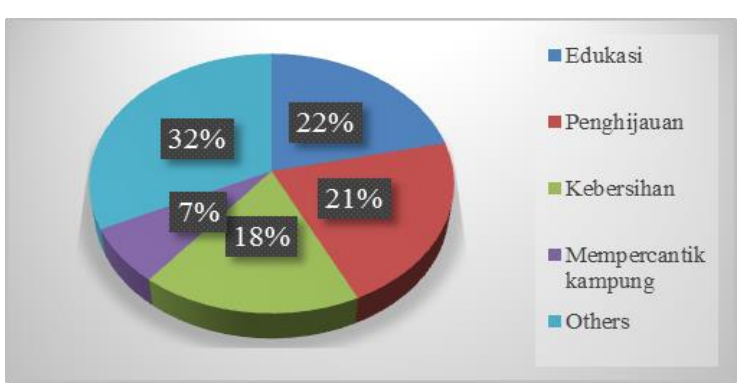

Gambar 8. Grafik Responden Berdasarkan Ide untuk Topik Kegiatan

2. Antusias warga untuk mengikuti kegiatan serupa setelah kegiatan SL

Dilihat dari Gambar 9, warga antusias untuk mengikuti kegiatan serupa. $11 \%$ tertarik untuk lomba 17 Agustusan, 14\% lomba untuk ibu-ibu, $14 \%$ kegiatan penghijauan, 29\% lomba di luar kampong mereka, dan $32 \%$ memilih kegiatan lainnya.

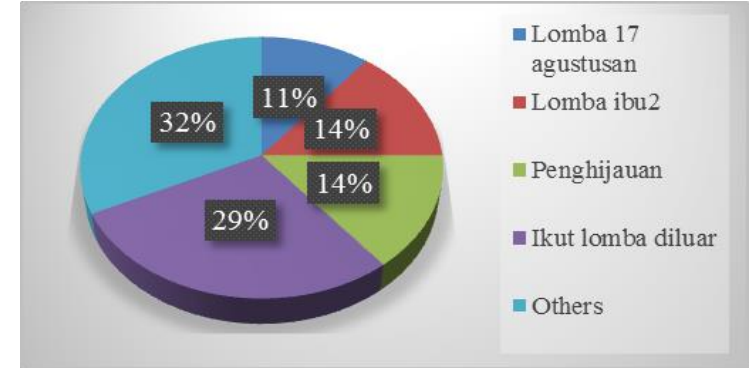

Gambar 9. Grafik Responden Berdasarkan Antusias Warga untuk Mengikuti Kegiatan Serupa

3. Kesuksesan acara

Dilihat dari gambar 10, terdapat beberapa alasan dari responden mengenai kesuksesan acara. $50 \%$ mengatakan acara seru dan ramai, $11 \%$ mengatakan banyak teman, $25 \%$ mengatakan kompak, 7\% mengatakan kreatif, dan 7\% mengatakan alasan lainnya.

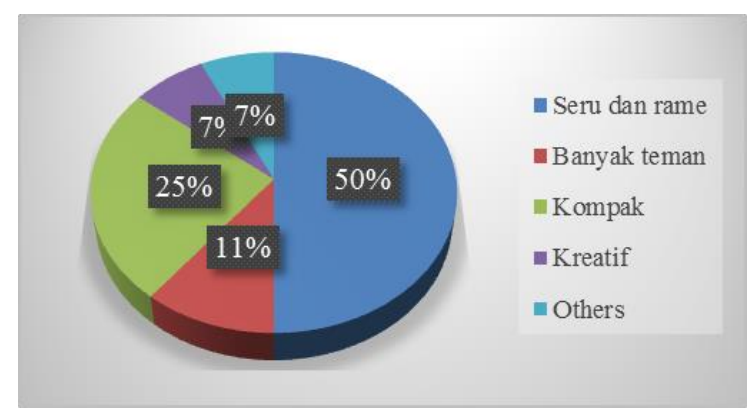

Gambar 10. Grafik Responden Berdasarkan Pendapat Warga Tentang Kesuksesan Acara

\section{KESIMPULAN}

Berdasarkan kegiatan service learning ini, dapat disimpulkan beberapa hal, yaitu:

1) Berdasarkan hasil yang diperoleh, dapat disimpulkan bahwa para peserta paham tentang lingkungan yang bersih dan sehat dan antusias untuk mengikuti kegiatan serupa jika ada.

2) Kegiatan service learning ini dapat dikatakan sebagai kegiatan yang cukup berhasil mencapai tujuannya, yaitu untuk memberi pembelajaran khususnya bagi anak-anak di wilayah Putat Jaya agar mereka menyadari pentingnya menjaga kebersihan lingkungan dan menanamkan rasa peduli terhadap lingkungannya dimulai dari kecil. Hal ini ditunjukkan dari gambar yang terdapat di tempat sampah bersama dengan pesan-pesan yang ingin disampaikan dengan adanya tempat sampah tersebut.

\section{UCAPAN TERIMA KASIH}

Atas berlangsungnya program ini, kami mengucapkan terima kasih sebesar-besarnya pada segala pihak yang telah membantu secara langsung maupun tidak langsung sehingga program ini dapat 
berjalan dengan baik dari awal hingga akhir. Kegiatan ini tidak dapat berlangsung apabila tidak ada kontribusi dari berbagai pihak, antara lain:

1. Program Studi Teknik Sipil UK Petra Surabaya.

2. Lembaga Penelitian dan service learning UK Petra Surabaya.

3. Lurah Kelurahan Putat Jaya Kecamatan Sawahan Surabaya.

4. Ketua RW 05 Kelurahan Putat Jaya, Ketua RT 03 RW 05 dan RT 04 RW 05.

5. Kelurahan Putat Jaya.

6. Warga RT 03 RW 05 dan RT 04 RW 05 Kelurahan Putat Jaya.

7. Seluruh peserta kegiatan service learning yang merupakan mahasiswa Program Studi Teknik Sipil UK Petra Surabaya.

\section{DAFTAR PUSTAKA}

Andreas, Damianus. 2017. Urbanisasi di Indonesia Lebih Tinggi daripada Cina. Diambil dari: https://irto.id/urbanisasi-di-indonesia-lebihtinggi-daripada-cina-cBZc. Diakses tanggal 29 November 2018.

Berita Nasional. 2017. Pertumbuhan Urbanisasi Indonesia Tertinggi di Dunia, Kebutuhan Rumah Jadi Masalah. Diambil dari: https://kbr. id/nasional/03-2017/pertumbuhan_urbanisasi_ indonesia_tertinggi_di_dunia_kebutuhan_rum ah_jadi_masalah/89430.html. Diakses tanggal 29 November 2018.

Greentumble Editorial Team. 2016. Environmental Problems of Urbanization. Diambil dari: https://greentumble.com/environmental-problems-of-urbanization/. Diakses tanggal 28 November 2018.

Hermawan, S., Purnomo, J., Prayogo, H., Handoyo, H., Setiawan, J. 2018. Pembangunan Smoking Area Untuk Meningkatkan Kualitas Hidup Masyarakat Di Kawasan Eks-Lokalisasi Dolly. SHARE: "SHaring-Action-REflection", 4(1), 2936.

Hermawana, S. Gho, D. 2019. Application and Lesson Learned in Civil Engineering, Environmental Science Service-Learning Program, Proceeding: APRCSL 2019,The 7th Asia-Pacific Regional Conference on Service-Learning.

Hermawan $^{b}$, S. Sutandi, P. Setiawan, A. William, S. Sumarno, K. 2019. Penerapan Kebiasaan Cuci
Tangan Sejak Dini Untuk Perubahan Perilaku Hidup Sehat. Jurnal LeECOM, volume: special Seminar Nasional Pengabdian Masyarakat I Universitas Ciputra.

Hermawan', S. Prayogo, N. Prayogo, D. 2019. Kampung Warna Warni Berperilaku Hidup Sehat dan Bersih. Jurnal LeECOM, volume: special Seminar Nasional Pengabdian Masyarakat I Universitas Ciputra.

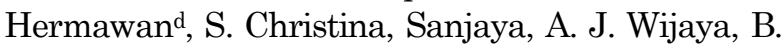
H. Gaby, G. 2019. Pemberdayaan Masyarakat Kampung Putat Jaya dengan Membangun Kolam Ikan Lele. Jurnal LeECOM, volume: special Seminar Nasional Pengabdian Masyarakat I Universitas Ciputra.

Katz, David L. 2018. Improve Your Health Habits to Benefit the Environment. Diambil dari: https://www.verywellfit.com/healthy-habitsbenefit-the-environment-4071938. Diakses tanggal 22 November 2018.

Kyriakides, Robert. 2010. If We Do Not Care for the Environment, the Environment Will Not Care for Us. Diambil dari: https://robertkyriakides. wordpress.com/2010/08/20/if-we-do-not-care-forthe-environment-the-environment-will-notcare-for-us/. Diakses tanggal 28 November 2018.

MateriIPS.com. 2017. 7 Faktor Pendorong Urbanisasi yang Terjadi di Daerah Asal. Diambil dari: https://materiips.com/faktor-pendorong-urbanisasi. Diakses tanggal 28 November 2018.

Ruiz, Alexia Elejalde. 2008. Habits Bad for the Environment. Diambil dari: https://www.chicagotribune.com/lifestyles/sns-gl-environmentenemies-story.html. Diakses tanggal 28 November 2018.

Wikipedia Bahasa Indonesia. 2018. Urbanisasi. Diambil dari: https://id.wikipedia.org/wiki/ Urbanisasi. Diakses tanggal 21 November 2018.

Wikipedia Bahasa Inggris. 2018. Human Impact on the Environment. Diambil dari: https://en.wikipedia.org/wiki/Human_impact_on_the_environ ment. Diakses tanggal 28 November 2018.

Wiwaha, Arjuna. 2013. Daerah Pinggiran Kota (Urban Fringe). Diambil dari: http://studyandlearningnow.blogspot.com/2013/01/daerahpinggiran-kota-urban-fringe.html. Diakses tanggal 25 November 2018. 